\title{
Moraxella keratitis in a nonalcoholic population
}

\author{
L. MICHAEL COBO, D. J. COSTER, AND JOHN PEACOCK
}

From the Institute of Ophthalmology, Departments of Clinical Ophthalmology and Pathology, University of London, and Moorfields Eye Hospital, City Road, London

SUMMARY Moraxella keratitis has been commonly described as a disease of debilitated older patients, particularly malnourished chronic alcoholics. This communication reviews the features of corneal infection due to Moraxella nonliquifaciens occurring in both young and old patients in otherwise good general health. Chronic corneal epithelial disturbance was a common finding in the 8 patients reported, indicating that more localised corneal debilitation may have a role in the pathogenesis of this disease.

The purpose of this communication is to review the features of corneal infection due to moraxella as observed in a series of 8 consecutive patients seen at Moorfields Eye Hospital, City Road, London. Moraxella is an important cause of bacterial keratitis. In the period of observation of these 8 cases it has been exceeded in frequency only by Streptococcus pneumoniae, staphylococcus, and pseudomonas species in investigated cases of suppurative keratitis where bacteria were isolated.

It is a popularly held misconception that moraxella keratitis is a disease of debilitated older patients, particularly malnourished chronic alcoholics. ${ }^{1-3} \mathrm{We}$ here report 8 cases of corneal infection due to Moraxella nonliquifaciens occurring in both young and old patients in otherwise good general health, with a predilection noted for eyes with chronic corneal epithelial disturbance.

\section{Patients and methods}

The 8 cases reported presented during a period of 15 months. Characteristics of the individual patients are noted in Table 1 along with laboratory results. In this series adults of working age were seen and chronic alcoholism was not a feature of any patient. Corneal scrapings were done, when possible, without topical anaesthetics.

An organism was considered to have a pathogenic role in the disease if 2 separate identifications were achieved, that is, an organism was seen in the Gram stain and cultured on 1 inoculation or, alternatively, cultured from 2 or more separate inoculations.

Correspondence to L. Michael Cobo, MD. Duke University Eye Center, PO Box 3802, Durham, NC 27710, USA.
Identification was based on the classification and methods described by Cowan. ${ }^{4}$ Although we have designated the moraxella strains isolated as $M$. nonliquifaciens, our test results do not exclude $M$. osloenis. ${ }^{5}$

Moraxella nonliquifaciens was identified in each case on the morphological appearance, characteristically a plump Gram-negative diplobacillary shape, nonmotility, and obligatory aerobic growth. All strains grew on nutrient agar without the addition of blood or serum, and the catalase and oxidase tests

Table 1 Details of patients

\begin{tabular}{|c|c|c|c|c|c|c|}
\hline Patient & Sex & Age & $\begin{array}{l}\text { General } \\
\text { health }\end{array}$ & $\begin{array}{l}\text { Pre-existing } \\
\text { ocular disease }\end{array}$ & $\begin{array}{l}\text { Gram } \\
\text { stain }\end{array}$ & Culture \\
\hline 1 & $\mathbf{M}$ & 54 & Good & $\begin{array}{l}\text { Corneal oedema, } \\
\text { Corneal birth trauma }\end{array}$ & + & + \\
\hline 2 & $\mathbf{M}$ & 59 & Good & $\begin{array}{l}\text { Herpetic keratitis. } \\
\text { corneal graft, allograft } \\
\text { rejection, recurrent } \\
\text { herpes simplex } \\
\text { keratitis }\end{array}$ & + & $-^{*}$ \\
\hline 3 & $\mathbf{F}$ & 10 & $\begin{array}{l}\text { Asthma. } \\
\text { eczema }\end{array}$ & Vernal conjunctivitis & + & + \\
\hline 4 & $\mathbf{F}$ & 68 & Good & $\begin{array}{l}\text { Traumatic corneal } \\
\text { abrasion }\end{array}$ & + & + \\
\hline 5 & $\mathbf{F}$ & 75 & Diabetes & $\begin{array}{l}\text { Epithelial basement } \\
\text { membrane dystrophy, } \\
\text { s/p cataract extraction }\end{array}$ & + & + \\
\hline 6 & $\mathbf{F}$ & 74 & $\begin{array}{l}\text { Hyper- } \\
\text { tension }\end{array}$ & $\begin{array}{l}\text { Central retinal vein } \\
\text { occlusion, rubeotic } \\
\text { glaucoma, corneal } \\
\text { oedema }\end{array}$ & $\begin{array}{l}\text { Not } \\
\text { done }\end{array}$ & + \\
\hline 7 & $\mathbf{F}$ & 59 & Good & $\begin{array}{l}\text { Interstitial keratitis } \\
\text { band keratopathy, } \\
\text { chronic blepharitis }\end{array}$ & + & + \\
\hline 8 & $\mathbf{M}$ & 43 & $\begin{array}{l}\text { Poikilo- } \\
\text { derma }\end{array}$ & Chronic blepharitis & + & + \\
\hline
\end{tabular}

*Positive after subculture of initial specimen. 
were positive. Three strains grew weakly on Simmons's citrate agar; the other 5 strains failed to grow. Seven of the 8 strains reduced nitrates to nitrites. None of the strains grew on MacConkey's agar and no haemolysis was seen on blood agar. Oxidation or fermentation in Hugh and Leifson's media, containing dextrose and maltose, was not detected, and all other carbohydrate tests performed were negative. Urease production was negative, and all strains failed to liquefy gelatin at $37^{\circ} \mathrm{C}$ or at room temperature. Proteolytic activity was not detected on Loeffler's serum slopes.

On the basis of the initial Gram stain findings patients were treated at the time of diagnosis with topical gentamicin sulphate supplemented by subconjunctival injections of gentamicin or carbenicillin, depending on the degree of corneal involvement. One patient (case 6), followed up as an outpatient, in whom a Gram stain had not been done, was treated with topical chloramphenicol with resolution of the keratitis. Improvement of inflammatory signs was noted in all patients within 48 hours. The time required to heal the macroepithelial ulceration varied from 4 days (case 3 ) to 7 weeks (case 7) and appeared to depend on the severity of the pre-existing corneal disease. No patient in this series developed a perforation secondary to the keratitis. One patient, from whom moraxella was isolated during 2 clinically distinct episodes, is described in detail.

\section{CASE 1}

A 54-year-old male bank employee presented with a history of pain in the right eye of 24 hours' duration. Poor vision in this eye had previously been ascribed to birth trauma. He denied previous episodes of similar pain in the right eye but over the past 3 years had been treated for intermittent ocular irritation with topical antibiotics by his general physician. The patient was otherwise in good health. In the left eye vision was $6 / 5$ and ocular examination showed no abnormality. The visual acuity of the right eye was reduced to perception of hand movements with accurate projection of light. Conjunctival vessels were injected and purulent discharge was present. The corneal epithelium was diffusely irregular and oedematous with a $2 \times 4 \mathrm{~mm}$ central defect. The underlying stroma was thickened and opacified by infiltrate. A small hypopyon was present. Prominent vertical striae were present at the level of Descemet's membrane consistent with corneal birth trauma. Scanty Gram-negative diplobacilli and abundant polymorphonuclear leucocytes were identified microscopically in the corneal smears, and moraxella was isolated from the corneal cultures.

The patient was treated with topical gentamicin. Corneal inflammatory signs improved, the eye became comfortable over 4 days. An irregular and

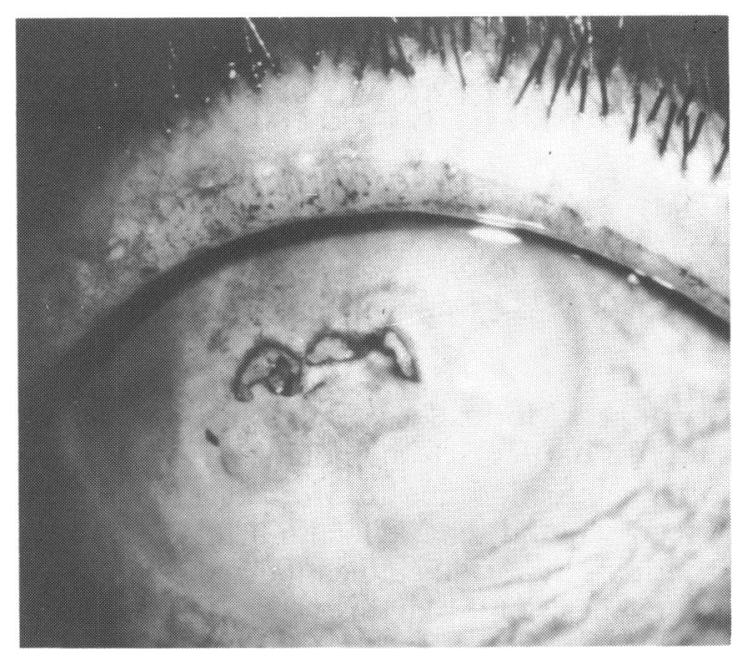

Fig. 1 Protruding epithelial plaques are outlined by rose Bengal stain in the absence of stromal infiltrate or inflammatory signs (case 1).

oedematous corneal surface persisted with central raised plaques.

The patient presented 5 months after discharge with a complaint of persistent foreign body sensation in the right eye. The eye was minimally injected and there was no purulent discharge. No epithelial defect was demonstrated with fluorescein but large central plaques within the epithelium protruded forward and stained with rose Bengal (Fig. 1). Stromal infiltrate was absent. Diffuse epithelial oedema which had persisted since the time of discharge made it difficult to judge anterior chamber reaction, but there was no hypopyon. The plaques were removed. Gram stain revealed many Gram-negative diplobacilli within epithelial cell debris (Fig. 2), and absence of inflammatory cells. Moraxella was isolated from the cultures taken. The cornea re-epithelialised, but the patient continued to complain of minor foreign body sensation on topical chloramphenicol drops.

\section{Discussion}

Over a 15-month period 8 cases of bacterial keratitis due to Moraxella nonliquifaciens were observed in patients ranging in age from 10 to 74 years and in otherwise good general health. This is contrary to the characterisation of moraxella keratitis as a disease of elderly, alcoholic, or chronically debilitated patients. ${ }^{1-3}$ In the 8 patients reported here 5 are under 60 years, those of working age were gainfully employed, and in no case was chronic alcoholism a feature.

Moraxella is commonly found in the normal flora 


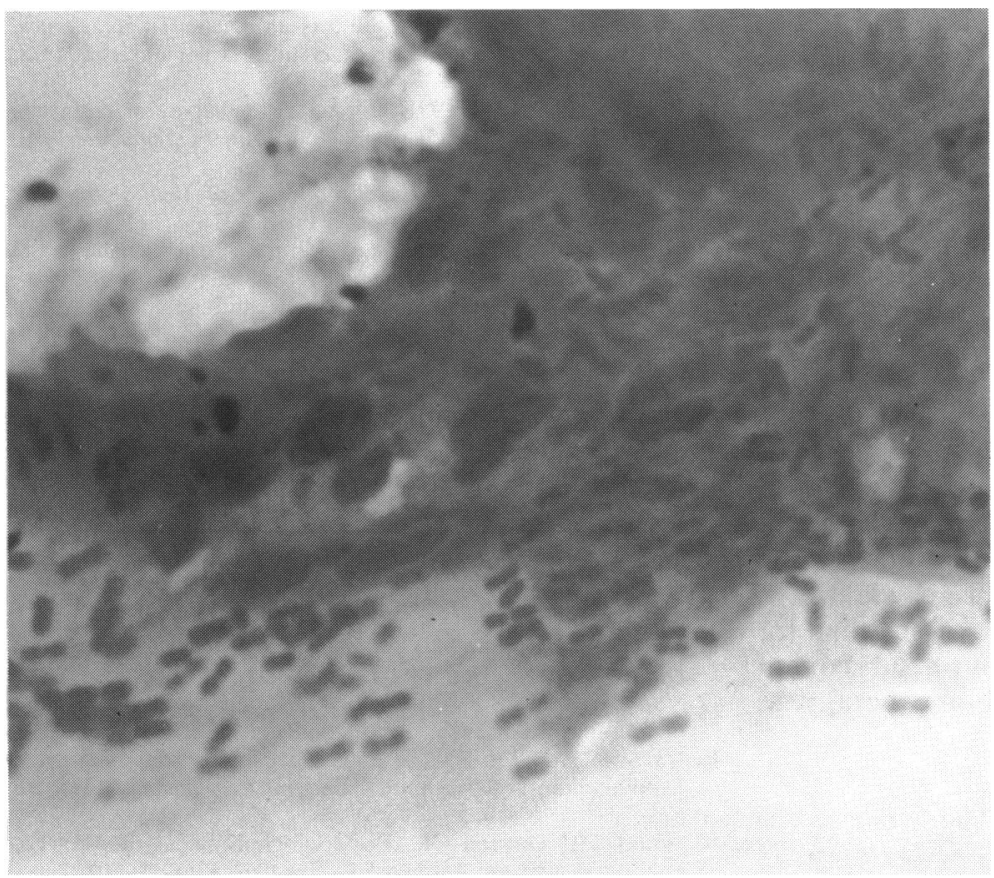

Fig. 2 Gram stain of plaques (case 1) demonstrating Gram-negative diplobacilli adherent to degenerative epithelium and mucus without inflammatory cells. $(\times 1100)$.

of the upper respiratory tract but is rarely seen in the normal conjunctival flora. ${ }^{56}$ As a pathogen moraxella has been implicated primarily in ocular infections, most frequently in angular blepharoconjunctivitis. ${ }^{7}$ As a cause of angular blepharoconjunctivitis moraxella has been said to be most readily identified in the macerated, cornified epithelial cells about the outer canthus. ${ }^{8}$ It has been suggested that these cells may provide nutrients for this adherent fastidious organism. ${ }^{89}$ More recent reviews indicate that moraxella is no longer a significant cause of angular blepharitis in urban communities, ${ }^{1011}$ presumably because of improved hygiene and nutrition. ${ }^{12}$ Further substantiation of the role of nutrition is demonstrated in the observed decline in moraxella keratitis in a derelict population during a period of improved nutrition and sanitation while the incidence of alcoholism remained unchanged. ${ }^{3}$ However, moraxella has been isolated in significant proportions of elderly patients in retirement communities ${ }^{12}$ and in patients with hypovitaminosis A xerophthalmia ${ }^{13}$ as well as inactive trachoma. ${ }^{14}$ This may indicate a propensity for moraxella to multiply and assume a pathogenic role in disease states where alterations of the lids or conjunctival or corneal epithelium may exist.

Abnormalities of corneal epithelial, often chronic, were present in 7 of the 8 patients in this series before the onset of moraxella keratitis (cases 1 to 7), indicating that more local corneal debilitation may provide abnormal epithelial cells to which organisms may adhere as they do in the macerated epithelium of angular blepharitis. The predilection for abnormal corneal epithelium is notable in case 1 , where moraxella was identified and isolated on 2 separate and clinically distinct occasions. Moraxella was first isolated in this patient during an episode of suppurative keratitis with epithelial ulcerations and stromal infiltration accompanied by a hypopyon. Five months later the removal of an irritating corneal plaque at a time when signs of active infection were absent revealed masses of Gram-negative diplobacilli in the epithelial and mucous plaques accompanied by a positive culture but lacking the inflammatory cells present in the initial episode of suppurative keratitis. This implies that moraxella may exist and adhere to an abnormal corneal epithelium without manifesting infection clinically.

Moraxella keratitis has previously been characterised as a central ulceration with deep stromal involvement, hypopyon, and a tendency to perforation. ${ }^{1}$ Patients reported in this series, however, would indicate that pre-existing corneal disease probably determines ulcer morphology and location and that the degree of stromal involvement is variable. Corneal perforation did not occur in this series.

Moraxella is generally highly sensitive to a wide range of antibiotics, including the penicillins. This sensitivity, coupled with fastidious growth requirements, may account for difficulties in isolating the 
organism if the patient has been on long-term topical medications (case 2) or if anaesthetics are used in obtaining cultures. Preservatives in drug solutions as well as anaesthetics themselves are known to inhibit growth of other less fastidious bacteria. ${ }^{16}$ While Havener ${ }^{17}$ states that 'corneal scraping is impossible without an anaesthetic,' our experience has been that one can routinely take corneal cultures without a topical anaesthetic, causing the patient little or no discomfort and potentially increasing the opportunity of identifying the infecting microbe. Identification of plump Gram-negative diplobacilli allows one to make a presumptive diagnosis of moraxella infection, but it is emphasised that these patients must be treated as having potentially more virulent Gram-negative infections until cultures confirm the results of the Gram-stained smear. Once the organism is identified, one generally has a wider antibiotic choice than for other Gram-negative organisms, and a subsequent satisfactory response to topical antibiotic therapy, as in these 8 patients, is to be expected.

The authors thank those surgeons of Moorfields Eye Hospital who kindly referred individual patients to us.

\section{References}

1 Fedukowicz $\mathrm{H}$, Horwich $\mathrm{H}$. The Gram-negative diplobacillus in hypopyon keratitis. Arch Ophthalmol 1953; 49: 202-11.
2 Wilson LA. Bacterial corneal ulcers. In: Duane Td, ed. Clinical Ophthalmology. Hagerstown, Maryland: Harper and Row, 1978: 4: chapter 18: 3-8.

3 Baum J, Fedukowicz HB, Jordan A. A survey of moraxella corneal ulcers in a derelict population. Am J Ophthalmol 1980; 90: 476-80.

4 Cowan ST. Manual for the Identification of Medical Bacteria. Cambridge: Cambridge University Press, 1974.

5 Henriksen SD. Moraxella, neisseria, branhemella, and acinetobacter. Ann Rev Microbiol 1976; 30: 63-83.

6 Smith $\mathrm{CH}$. Bacteriology of the health conjunctiva. $\mathrm{Br} \mathrm{J}$ Ophthalmol 1954; 38: 719-26.

7 Morax V. Note sur un diplobacille pathogène pour la conjunctivite humaine. Ann Inst Pasteur 1896; 10: 337-45.

8 Howard $\mathrm{HJ}$. Role of the epithelial cell in conjunctival and corneal infections. Am J Ophthalmol 1924; 7: 909-36.

9 Van Bijsterveld OP. Host-parasite relationship and taxonomic position of moraxella and morphologically related organisms. Am J Ophthalmol 1973; 76: 545-54.

10 Jones BR, Andrews BE, Henderson WG, Shofield PB. The pattern of conjunctivitis at Moorfields during 1956. Trans Ophthalmol Soc UK 1957; 77: 291-305.

11 Thygeson P, Kimura SJ. Chronic conjunctivitis. Trans Am Acad Ophthalmol Otolaryngol 1963; 67: 494-517.

12 Van Bijsterveld OP. The incidence of moraxella on mucous membranes and the skin. Am J Ophthalmol 1972; 74: 72-6.

13 Valenton MJ, Tan RV. Secondary ocular bacterial infection in hypovitaminosis A xerophthalmia. Am J Ophthalmol 1975; 80: 673-7.

14 Wood TR, Dawson CR. Bacteriological studies of a trachomatous population. Am J Ophthalmol 1967; 63: 1298-301.

15 Vastine DW, Dawson CR, Daghfous D, et al. Severe endemic trachoma in Tunisia. Br J Ophthalmol 1974; 58: 833-42.

16 Kleinfeld J, Ellis PP. Effects of topical anaesthetics on growth of microorganisms. Arch Ophthalmol 1966; 76: 712-5.

17 Havener WH. Ocular Pharmacology. St Louis: Mosby, 1978: 72. 